\title{
ASSISTÊNCIA TÉCNICA EM HABITAÇÃO DE INTERESSE SOCIAL PARA PROMOÇÃO DO HABITAT SAUDÁVEL
}

\author{
TECHNICAL ASSISTANCE IN SOCIAL HOUSING FOR THE PROMOTION OF HEALTHY \\ HABITAT
}

\author{
Josiane Andréia Scotton ${ }^{1}$, Luciana Ines Gomes Miron ${ }^{1}$, Inês Martina Lersch²
}

\section{RESUMO:}

A precariedade das condições de moradia no Brasil tem sérias implicações sobre o habitat saudável. No ano de 2020, o advento da pandemia de Covid-19 acrescentou urgência às discussões acerca da habitação saudável, principalmente nas periferias das cidades; onde se encontram as maiores carências: de habitabilidade, de fornecimento de água, de infraestrutura e saneamento básico. Nesse contexto, a aplicação da Lei 11.888 de 2008, da Assistência Técnica em Habitação de Interesse Social (ATHIS), tem oportunizado o acesso ao trabalho dos profissionais de arquitetura para a população de baixa renda. Além disso, as iniciativas de ATHIS têm buscado a consolidação de projetos de habitação de interesse social que resultem na produção de unidades habitacionais mais saudáveis. O presente artigo apresenta um estudo de caso sobre o processo de desenvolvimento da ATHIS para uma comunidade de 68 famílias da cidade de São Leopoldo, Região Metropolitana de Porto Alegre, estado do Rio Grande do Sul. O objetivo deste estudo é compreender como o processo de ATHIS pôde contribuir para a promoção do habitat saudável naquela comunidade. As técnicas de coleta de dados utilizadas foram: análise de documentos, observação assistemática não-participante e entrevistas semiestruturadas. Os resultados permitiram constatar que: i) a ATHIS envolvendo a população através de processo participativo, apresenta contribuições para a melhoria das condições de habitabilidade das populações envolvidas; ii) a ATHIS pode contribuir para a consolidação de um habitat saudável através da melhoria da qualidade do ambiente urbano e habitacional, destacando-se as condições básicas de saneamento.

PALAVRAS-CHAVE: Habitat Saudável; habitação de interesse social; assistência técnica; participação.

\section{ABSTRACT:}

The precariousness of housing conditions in Brazil has serious implications for healthy habitat. In the year 2020, the advent of the Covid-19 pandemic, added urgency to the discussions about healthy housing, especially on the outskirts of cities; where the greatest needs are found: habitability, water supply, infrastructure and basic sanitation. In this context, the application of Law 11,888 of 2008, of Technical Assistance in Social Housing (ATHIS), has provided opportunities for the work of architecture professionals for the low-income population. In addition, ATHIS initiatives have sought to consolidate social housing projects that result in the production of healthier housing units. This article presents a case study on the ATHIS development process for a community of 68 families in the city of São Leopoldo, Metropolitan Region of Porto Alegre, state of Rio Grande do Sul. The objective of this study was to understand how ATHIS process can contribute to the promotion of healthy habitat for low-income populations. The data collection techniques used were: document analysis, non-participant unsystematic observation and semi-structured interviews. The results showed that: i) ATHIS involving the population through a participatory process, contributes to the improvement of the habitability conditions of the populations involved; ii) ATHIS can contribute to the consolidation of a healthy habitat by improving the quality of the urban and housing environment, with emphasis on basic sanitation conditions.

KEYWORDS: Healthy Habitat; social housing; technical assistance; participation.

How to cite this article:

SCOTTON, Josiane Andréia; MIRON, Luciana Ines Gomes; LERSCH, Inês Martina . Assistência Técnica em Habitação de Interesse Social para Promoção do Habitat Saudável. Gestão \& Tecnologia de Projetos. São Carlos, v16, n4, 2021. https://doi.org/10.11606/gtp.v16i4.178679
1Programa de PósGraduação em Planejamento Urbano e Regional (PROPUR). Universidade Federal do Rio Grande do Sul UFRGS

2Programa de PósGraduação em Planejamento Urbano e Regional (PROPUR). Universidade Federal do Rio Grande do Sul UFRGS

${ }^{3}$ Programa de PósGraduação em Planejamento Urbano e Regional (PROPUR). Universidade Federal do Rio Grande do Sul UFRGS

Fonte de Financiamento: Capes (Bolsa de Mestrado 2018-2020).

Conflito de Interesse: Declara não haver conflito de interesse.

Ética em Pesquisa:

Pesquisa aprovada pelo Comitê de Ética em Pesquisa (CEP)/ Plataforma Brasil na data de 10 de outubro de 2019, sob número CAAE: 19398719.6.0000.5347.

Submetido em: data de submissão: 10/04/2021 Aceito em: 20/04/2021

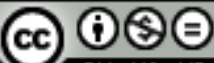




\section{INTRODUÇÃO: HABITAÇÃO, ATHIS E A PANDEMIA}

A precariedade das condições de moradia no Brasil tem forte relação com a intensificação dos processos de urbanização e o consequente aumento das ocupações e favelas (MARICATO, 2002). A explosão habitacional das cidades do sul do mundo a partir da segunda metade do século XX, resultou em grandes aglomerados urbanos, em cujos territórios se manifestaram graves segregações de classes sociais (CARDOSO; AMORE, 2018, p. 1). A urbanização se concentrou nos setores habitados predominantemente pelas classes de alta renda, relegando à população mais pobre as periferias, as favelas, os cortiços e os loteamentos populares, cujas características comuns parecem ser a distância dos principais locais de oferta de empregos, bem como a precariedade através da falta de infraestrutura, de equipamentos públicos, de comércio e serviços (CARDOSO; AMORE, 2018, p. 1).

A Fundação João Pinheiro (FJP) busca quantificar esse tipo de precariedade através do conceito de déficit habitacional qualitativo, o qual se refere aos domicílios com alguma inadequação (FJP, 2018). Em 2015, a FJP identificou que os domicílios com alguma inadequação ultrapassavam os 9 milhões, englobando carência de infraestrutura (7.225 milhões de domicílios), cobertura inadequada (834 mil domicílios) e adensamento excessivo (1.025 milhões domicílios) (FJP, 2018). Cerca de 47,1\% dos domicílios inadequados em termos fundiários, bem como os domicílios com cobertura inadequada pertencem às famílias brasileiras com renda de até 3 salários-mínimos (FJP, 2018).

Dados complementares apontam ainda que no Brasil, $56,2 \%$ da população não tem acesso ao esgotamento sanitário; e 25,8\% (13,5 milhões) não é atendida com abastecimento de água por rede (NERY, 2019). Contexto também ressaltado por Nascimento (2020, p. 2), ao afirmar que 35 milhões de brasileiros não tem acesso à água para lavar as mãos (com base em dados do Instituto Trata Brasil). Segundo Betim (2015), a carência de rede de esgoto, ventilação interna e de incidência solar são características presentes em muitas destas habitações e são fatores que podem resultar em doenças como bronquite, meningite, tuberculose, depressão, etc. No ano de 2013, por exemplo, a Favela da Rocinha (RJ) registrou mais de trezentos casos de tuberculose (BETIM, 2015). Assim, o perfil da inadequação habitacional no Brasil apresenta como características predominantes: a concentração nas famílias de baixa renda e a precariedade das condições urbanas e habitacionais (carência de saneamento básico e de condições mínimas de habitabilidade), o que, por sua vez, resulta em espaços inseguros (em termos construtivos) e insalubres (sem condições de saneamento básico).

No ano de 2020, o advento da pandemia de Covid-19 acrescentou urgência às discussões acerca da habitação saudável, especialmente em suas dimensões sanitárias. A pandemia somou-se aos problemas estruturais da sociedade brasileira (CANETTIERI, 2020, p. 51). Os quadros de precariedade prejudicam os cuidados de prevenção mínimos no contexto da pandemia, a saber, a higienização das mãos, de suprimentos e da habitação, bem como, expõem a necessidade de promover habitações saudáveis e seguras para a população de baixa renda: com habitabilidade, saneamento básico e condições mínimas para o cumprimento dos protocolos preventivos.

Nesse cenário, estão as discussões sobre a Assistência Técnica para Habitação de Interesse Social (ATHIS), cujas ações buscam democratizar o acesso aos serviços de Arquitetura e Urbanismo, ao se focar em atender as necessidades específicas da habitação para a população de baixa renda. Nesse sentido, a Lei de Assistência Técnica, Lei 11.888 de 2008 (BRASIL, 2008), se apresenta como um importante instrumento na luta para a conquista de uma moradia digna e saudável. Com base nessa lei, diversas iniciativas têm sido realizadas pelo país, a exemplo das ações patrocinadas pelo Conselho de Arquitetura e urbanismo (CAU) em diferentes estados, como o programa "Nenhuma Casa sem Banheiro" do CAU-RS. Além disso, são exemplos relacionados à prática de ATHIS: os projetos de extensão realizados dentro das Universidades 
(D'OTTAVIANO; ROVATI, 2017; D'OTTAVIANO; ROVATI, 2019; MELLO et al., 2019; MELLO et al., 2020), além das ONGs e escritórios que se articulam de maneira independente (como a ONG Peabiru TCA ${ }^{1}$, de SP e o Escritório AH! Arquitetura Humana ${ }^{2}$, de Porto Alegre/RS) ${ }^{3}$. Esse contexto atual da prática de ATHIS também é exemplificado por Cardoso e Amore (2018) ao mencionarem que alguns dos grupos de assessorias que surgiram em décadas passadas continuam atuando junto aos movimentos sociais, em projetos de melhorias habitacionais, produção de novas unidades e urbanização de favelas. Segundo os autores, "esse trabalho ainda atinge uma pequena parcela da população brasileira, e se desenvolve a partir de experiências locais." (CARDOSO; AMORE, 2018, p. 2).

Contudo, esses autores salientam que a Lei ainda é pouco efetiva, pois mesmo após 10 anos de sua existência, poucas ações se concretizaram, longe de atingir um número representativo da população e de se consolidar como uma política habitacional. Mesmo assim, as ações e discussões que envolvem a temática têm contribuído para a consolidação da ideia de que os projetos de habitação de interesse social (HIS) devem trazer consigo a busca pela produção de unidades habitacionais mais saudáveis, atendendo às condições mínimas de saneamento básico e de segurança construtiva. Além disso, o uso de abordagens participativas de projeto tem buscado aproximar os profissionais de projeto das comunidades atendidas, possibilitando um melhor atendimento das necessidades específicas da população de baixa renda.

A partir desse contexto, o presente artigo aborda a assistência técnica para habitação de interesse social como um caminho para a promoção habitat saudável, bem como a importância da participação durante o seu processo de desenvolvimento. Nesse sentido, ao apresentar um estudo de caso sobre o processo de desenvolvimento da ATHIS para uma comunidade de 68 famílias da cidade de São Leopoldo/RS, busca analisar as abordagens participativas no desenvolvimento do projeto, bem como identificar as suas contribuições na promoção de um habitat mais saudável naquela comunidade ${ }^{4}$

\section{A ATHIS E OS PROCESSOS PARTICIPATIVOS DE PROJETO}

Na década de 1950, foram intensificadas as discussões acerca da assistência técnica em arquitetura e urbanismo, bem como a aproximação dos profissionais da área com as periferias e movimentos sociais; consolidando, a partir disso, as primeiras ações práticas que buscavam a democratização da arquitetura. Nas cidades de São Paulo e Rio de Janeiro foram registradas importantes e pioneiras experiências junto às periferias.

Em São Paulo, a prática das assessorias se consolidou a partir de ações pontuais e militantes que foram viabilizadas nos órgãos públicos, em universidades, em entidades de classe e a partir de ações da igreja católica (AMORE, 2004). Já na capital carioca, a experiência em Brás de Pina (1969) com o arquiteto Carlos Nelson Ferreira dos Santos, suscitou importantes discussões sobre as favelas e suas dimensões na cidade, apresentando um novo olhar sobre esses espaços a partir do contato direto dos profissionais com os moradores e suas demandas. Foi um dos

\footnotetext{
1 Site: http://www.peabirutca.org.br.

2 Site: http://ah.arq.br

${ }^{3}$ Essas iniciativas são independentes e pontuais, apesar de terem como base a Lei 11.888 - Lei de Assistência Técnica, na maioria das vezes elas não contam com recursos públicos. Não se trata, portanto, de uma política pública.

40 presente estudo faz parte de uma pesquisa maior, que compõe uma dissertação de mestrado (SCOTTON, 2020).
} 
primeiros projetos participativos a ser, de fato, executado por gestores estatais, sendo iniciado por uma mobilização popular no contexto da Ditadura Militar (SILVA, 2019).

Posteriormente, a partir de 1970, no Sindicato de Arquitetos do Estado do Rio Grande do Sul (SAERGS), tiveram início as discussões sobre a assistência técnica, que se direcionaram para a ideia de criação de legislações que garantissem assistência técnica pública e gratuita para a população de baixa renda ( 0 a 3 salários mínimos). Essas discussões culminaram com a criação do programa Assistência Técnica para Moradia Econômica (ATME) ${ }^{5}$, em 1977, o qual foi base para a criação de legislações municipais e, mais recentemente no ano de 2008, para a criação da Lei de Assistência Técnica: Lei 11.888 (BRASIL, 2008).

O termo "Assistência Técnica" em si trata da prática de prestar auxílio, oferecer um serviço especializado de arquitetura e urbanismo a alguém, referindo-se à ação de assistir, de estar presente, de ajudar e prestar auxílio (HOUAISS, 2001). Segundo Amore (2019), no campo da arquitetura, a prática da ATHIS representa uma oportunidade à moradia digna e, em uma dimensão da política pública, assume uma perspectiva de universalização, isto é, a habitação digna e saudável não fica restrita a alguém que pode pagar (AMORE, 2019). Ainda segundo esse autor (AMORE, 2019), outra dimensão da ATHIS é a especificidade das leituras e das soluções possíveis no âmbito habitacional, reconhecendo as particularidades de cada lugar e dando soluções singulares, o que faz com que se olhe para os assentamentos populares (favelas, vilas, mocambos) em busca de soluções específicas para aquele local e com a participação daqueles moradores, isso em oposição às soluções gerais e genéricas que costumam se repetir para todas as famílias ou para todas as regiões do país.

Essas especificidades e necessidades podem ser identificadas e compreendidas através de abordagens participativas. A participação é composta pelas noções de "parte, ser parte de" (lat. part), e "agarrar, tomar" (lat. cipere), indicando uma ação voluntária e decidida (DOBRY, 2019). Segundo Oliveira (2014), quando há a estruturação de atividade participativa, diferentes atores estão envolvidos e o "fazer parte", "ser parte de" envolve a interação e o diálogo entre esses atores, pois só assim as diferentes partes podem se tornar um todo em comum.

Participação é, portanto, diálogo entre os diferentes atores que compartilham sua vivência e seu conhecimento para produzirem um novo conhecimento que será utilizado nas suas ações conjuntas em determinado contexto (OLIVEIRA, 2014, p. 11).

Além disso, Boldrini (2012) destaca que as estratégias participativas devem ser adaptadas ao contexto atual e pontua que a sua efetividade depende da construção de vínculos através da integração comunitária.

O debate sobre a participação na arquitetura é de longa data. No início dos anos 1970, Habraken (1970) atentou para a exclusão do indivíduo nos processos de decisão referentes ao

${ }^{5} 0$ programa ATME visava oferecer assistência técnica gratuita às famílias que não tinham condições de arcar com a assessoria profissional na construção de suas casas (LEITE, 2017). Uma faixa da população que utilizava os serviços de pessoas não habilitadas para execução de projetos e obras, sem ter a assistência técnica que lhe era devida (MELLO, 2014). Ainda, como indica a proposta do programa: "do Programa de Assistência Técnica ao Projeto e Construção de Moradia Econômica (Programa ATME), para pessoas carentes de recursos, nasce diretamente da consciência que os arquitetos, enquanto classe profissional, adquiriram do problema habitacional brasileiro. E exatamente a proposição do Programa ATME, nos termos do que se segue, visa contribuir, sob uma renovada perspectiva profissional, para a solução desse problema (SAERGS, 1977). 
projeto e à produção da sua moradia; e apontou a urgente necessidade de que o arquiteto criasse condições para que o morar (para além da casa como produto) fosse possível para o indivíduo (NASCIMENTO et al., p. 5, 2010). Décadas depois, Nascimento et al. (2010) apontam que as políticas habitacionais atuais ainda estão distantes de promover processos compartilhados de decisão na produção habitacional e salientam que são raros os exemplos de processos de projeto e de construção baseados no compartilhamento das decisões (NASCIMENTO et al., p. 5, 2010). Dessa forma, embora possa parecer óbvia a lógica de envolver o futuro morador nas decisões relativas ao seu espaço de morar, esses autores evidenciam que isso ainda é uma carência, especialmente na habitação de interesse social.

Além disso, o diálogo entre os atores envolvidos na prática participativa, potencializa a compatibilização das vontades e necessidades populares com o conhecimento técnico. Oliveira (2014) afirma que isso permite que os envolvidos se apropriem do processo e contribuam para o desenvolvimento de suas habitações, havendo uma desconstrução do conhecimento anterior tanto do saber técnico quanto do saber popular, sendo que ambos se transformam.

Complementarmente, Boldrini e Malizia (2020) apontam a participação como caminho para a melhoria do habitat, tornando-os mais duradouros e efetivos nas resoluções de problemas do habitat. E ainda, outros estudos (Pelli, 2007; Boldrini, 2012) indicam que os processos de melhoria de bairros que tendem a ser mais duradouros e a resolver os problemas da habitação de forma mais eficaz são justamente aqueles que se apoiam em processos participativos que garantem a relevância e apropriação das medidas de melhoria implementadas.

A partir desse contexto, este trabalho parte do pressuposto de que a assistência técnica realizada de forma participativa pode contribuir para a melhoria das condições de moradia das populações de baixa renda, promovendo o habitat saudável. Adicionalmente, busca evidenciar a importância da participação dos moradores na construção de um espaço de morar de maior qualidade. Entende-se que a melhoria da qualidade da moradia e a promoção do habitat saudável estão diretamente ligadas ao conceito de moradia digna. A moradia digna, por sua vez, deve atender aos sete requisitos ${ }^{6}$ essenciais definidos pelo Pacto Internacional dos Direitos Econômicos Sociais e Culturais: i) Segurança da posse; ii) Disponibilidade de serviços,

${ }^{6}$ a) Segurança legal de posse: Independentemente do tipo de posse, todas as pessoas deveriam possuir um grau de sua segurança, o qual garanta proteção legal contra despejos forçados, pressões incômodas e outras ameaças. B) Disponibilidade de serviços, materiais, facilidades e infraestrutura: todos os beneficiários do direito à habitação adequada deveriam ter acesso a água apropriada para beber, energia para cozinhar, aquecimento e iluminação, facilidades sanitárias, meios de armazenagem de comida, depósito dos resíduos e de lixo, drenagem do ambiente e serviços de emergência. c) Custo acessível: os custos financeiros de um domicílio associados à habitação deveriam ser a um nível tal que a obtenção e satisfação de outras necessidades básicas não sejam ameaçadas ou comprometidas. Estados-partes deveriam estabelecer subsídios habitacionais para aqueles incapazes de arcar com os custos da habitação, tais como formas e níveis de financiamento habitacional que adequadamente refletem necessidades de habitação. d) Habitabilidade: a habitação adequada deve ser habitável, em termos de prover os habitantes com espaço adequado e protegê-los do frio, umidade, calor, chuva, vento ou outras ameaças à saúde, riscos estruturais e riscos de doença. e) Acessibilidade: habitações adequadas devem ser acessíveis àqueles com titularidade a elas. A grupos desfavorecidos deve ser concedido acesso total e sustentável a recursos de habitação adequada. f) Localização: a habitação adequada deve estar em uma localização que permita acesso a opções de trabalho, serviços de saúde, escolas, creches e outras facilidades sociais. g) Adequação cultural: a maneira como a habitação é construída, os materiais de construção usados e as políticas em que se baseiam devem possibilitar apropriadamente a expressão da identidade e diversidade cultural da habitação (NAÇÕES UNIDAS, 1991). 
materiais, facilidades e infraestrutura; iii) Custo acessível; iv) Habitabilidade; v) Acessibilidade; vi) Localização e; vii) Adequação cultural (NAÇõES UNIDAS, 1991).

Há que se considerar que a moradia digna é um conceito teórico difícil de ser espacializado (FRIZZI; PINHO, 2019, p. 7), medido e avaliado. Assim, neste trabalho, para a análise da melhoria das condições de moradia, foram considerados, dentro dos sete requisitos, aqueles que poderiam ser total ou parcialmente contemplados no âmbito do processo participativo de desenvolvimento de ATHIS. Dessa forma, foram considerados os requisitos de: segurança da posse; disponibilidade de serviços e de infraestrutura; e habitabilidade. Esta última, em especial, pois se refere a uma habitação que provê aos moradores espaço adequado para protegê-los de frio, umidade, calor, chuva, vento; ou outras ameaças à saúde, como riscos estruturais e riscos de doenças (NAÇÕES UNIDAS, 1991). Portanto, é a partir desses requisitos que os resultados serão analisados.

\section{PROCEDIMENTOS METODOLÓGICOS}

Conforme mencionado, a estratégia de pesquisa utilizada foi o estudo de caso. 0 caso investigado foi a Ocupação Cerâmica Anita, na cidade de São Leopoldo, Região Metropolitana de Porto Alegre, capital do estado do Rio Grande do Sul. Na Ocupação Cerâmica Anita a assistência técnica foi desenvolvida por meio de processo participativo de projeto, o qual buscou proporcionar a melhoria da qualidade das condições de moradia de 68 famílias.

As técnicas de coleta de dados envolveram: análise de documentos, observação assistemática não-participante e entrevistas semiestruturadas. A pesquisa foi aprovada pelo Comitê de Ética em Pesquisa (CEP)/ Plataforma Brasil na data de 10 de outubro de 2019, sob número CAAE: 19398719.6.0000.5347.

Foram entrevistadas 15 pessoas envolvidas no processo de ATHIS, subdivididas em dois grupos. 0 primeiro grupo foi composto por 11 moradores da Ocupação e o segundo grupo foi composto por 4 arquitetos e urbanistas (técnicos) que conduziram o processo de projeto. A análise do conteúdo das entrevistas teve início com a escuta e uma pré análise das falas dos entrevistados. A partir disso, foram identificadas as categorias de análise através da convergência entre os requisitos do "Pacto Internacional dos Direitos Econômicos Sociais e Culturais" adotados neste trabalho (NAÇÕES UNIDAS, 1991) e as temáticas recorrentes nas falas dos participantes. Dessa forma, considerando as recomendações de Oliveira (2014) e Silva e Fossá (2015), buscou-se construir a tipificação do material coletado em campo e fazer a transição entre a empiria e a elaboração teórica, através do uso de categorias de análise que permitissem a compreensão do que está por trás das falas.

Foram consideradas seis categorias de análise que se referem à melhoria da qualidade da moradia e do espaço urbano: 1) moradia digna; 2) acesso à habitação e à cidade; 3) adequação às especificidades do morador; 4) melhoria da qualidade da moradia; 5) melhoria da qualidade urbana; e 6) segurança de posse.

A classificação das falas nessas categorias permitiu a organização de tabelas síntese por categoria. As respostas obtidas nas entrevistas foram somadas às percepções captadas através da observação assistemática não-participante para a elaboração dos resultados deste estudo.

\section{ESTUDO DE CASO: OCUPAÇÃO CER. ANITA - SÃO LEOPOLDO, RS}

A cidade de São Leopoldo fica na região metropolitana de Porto Alegre e tem população estimada de 236.835 habitantes (2019), sendo subdividida em 24 bairros (IBGE, 2010). A Ocupação Cerâmica Anita está localizada no Bairro Vicentina, área periférica na região oeste 
da cidade que conta com uma população de aproximadamente 13.140 habitantes (IBGE, 2010). Consolidou-se no ano de 2014 por meio da ocupação de um terreno público, o qual estava destinado a ser área verde de um loteamento. Inicialmente, a ocupação chegou a ter 150 famílias, sendo que no período de desenvolvimento desta pesquisa, eram 68 famílias. A condição inicial, no ano de 2014 (e que se estendeu até o ano de 2019), era de precariedade, com barracos erguidos sobre a lama, construídos com resíduos de madeira e materiais recolhidos pelos moradores na condição de catadores de resíduos sólidos. Não havia ruas estruturadas, apenas pequenos becos de passagem entre as casas onde o acúmulo de lixo era corriqueiro, bem como o esgoto ao céu aberto e as instalações clandestinas (gatos) de água e de energia elétrica. Eram escassas as habitações que apresentavam estrutura segura ou eram construídas com materiais de boa qualidade. Assim sendo, as principais questões urbanas e habitacionais a serem melhoradas na Ocupação Cerâmica Anita estavam diretamente relacionadas às condições mínimas de salubridade e habitabilidade.

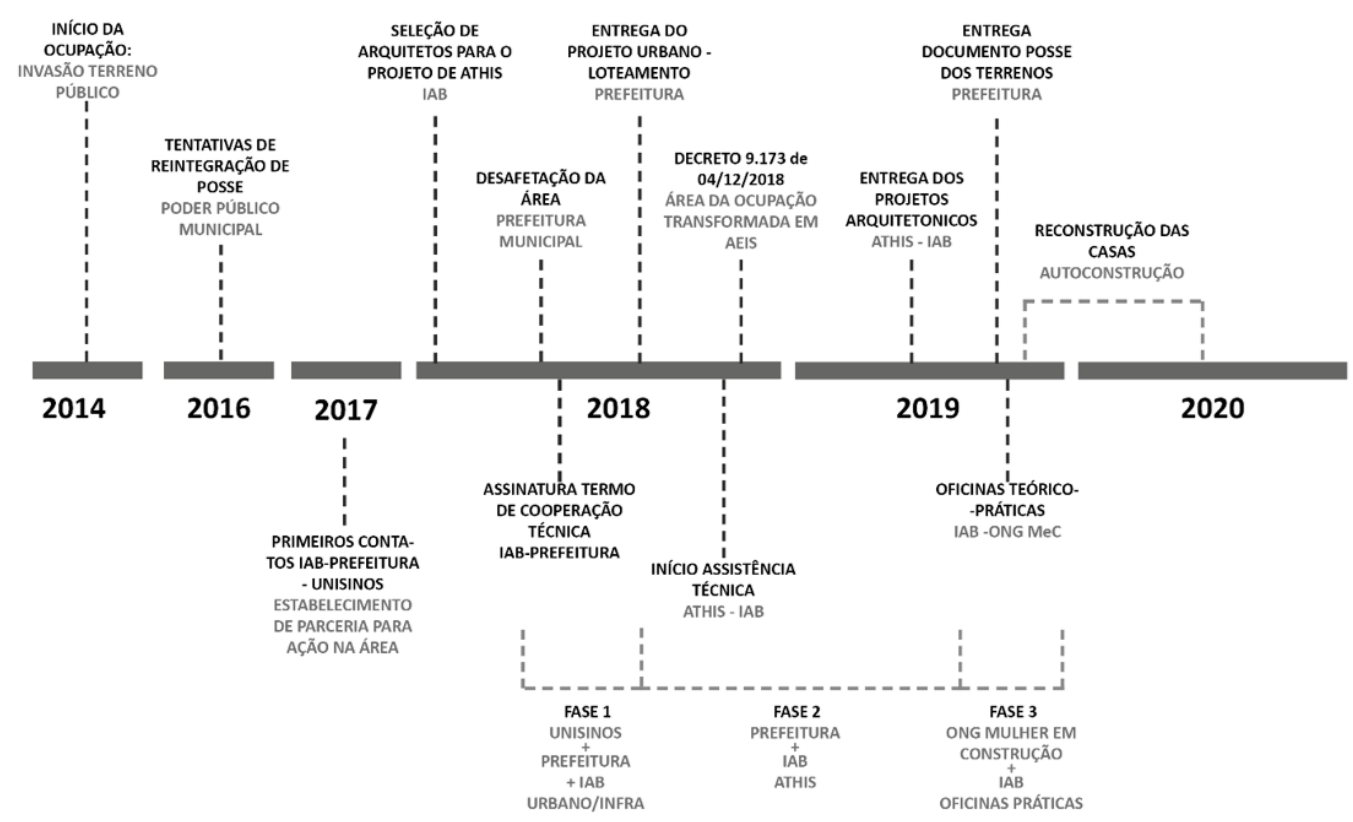

A Figura 1 apresenta uma de linha do tempo com o histórico da Ocupação Cerâmica Anita e os principais eventos relacionados ao processo de desenvolvimento da ATHIS. Conforme mencionado anteriormente, a ocupação teve início no ano de 2014, sendo que os processos de regularização fundiária e de ATHIS tiveram início a partir do ano de 2016, se estendendo até o ano de 2020 quando o local foi reconstruído pela própria comunidade, por autoconstrução.

\section{ANÁLISE DO PROCESSO DE ATHIS}

No ano de 2016, o poder público municipal manifestou a intenção de promover a regularização fundiária para fins habitacionais, da área onde se localizava a Ocupação. A regularização foi justificada pelo objetivo de garantir e democratizar o acesso à terra urbanizada, à moradia digna e aos serviços públicos; tendo em vista a permanência da população no local da ocupação consolidada.

A partir disso, os moradores da Ocupação Cerâmica Anita obtiveram no ano de 2018 a desafetação da área ocupada, garantindo sua permanência (FNA, 2018). 0 local foi instituído como Área Especial de Interesse Social I - AEIS, através do decreto no 9.173, de 04 de dezembro de 2018 (Prefeitura Municipal de São Leopoldo), com um total de 8.583,42m².
Figura 1. Linha do tempo da Ocupação C.A.

Fonte: Desenvolvida na pesquisa (SCOTTON, 2020) 
Regularizada a área, foi iniciada uma cooperação técnica entre a Prefeitura Municipal de São Leopoldo; a Universidade do Vale do Rio dos Sinos (UNISINOS), através do curso de Arquitetura e Urbanismo e seu Escritório Modelo (EMAU) e o Instituto de Arquitetos do Brasil, departamento do Rio Grande do Sul (IAB-RS). Os objetivos da cooperação foram: 1) fornecer infraestrutura e serviços urbanos; e 2) realizar projetos de habitações de interesse social para as 68 famílias residentes na Ocupação.

Para atender aos objetivos, a cooperação se estruturou em três fases: a primeira foi voltada à regularização fundiária da área e ao projeto urbanístico; a segunda envolveu a assistência técnica para os projetos das 68 habitações; e a terceira teve como foco a realização de oficinas prático-construtivas com os moradores da Ocupação, considerando que seria realizada a autoconstrução das habitações. Todas as fases contaram com a participação dos moradores da ocupação e das equipes técnicas das entidades envolvidas.

Na Fase 1, foi definido o desenho urbano para o local, que englobou 68 lotes e mais uma área pública para a comunidade, configurando uma área pública. Na Fase 2, a assistência técnica para os projetos habitacionais teve como foco o desenvolvimento dos projetos das habitações para as 68 famílias, a qual foi realizada através de processo participativo de projeto, onde as atividades incluíram encontros e oficinas envolvendo a comunidade, buscando integrar as famílias, fornecendo informações e incentivando-as a contribuir na construção do seu espaço de morar.

O primeiro encontro dos técnicos com a comunidade da ocupação possibilitou uma apresentação inicial, onde foi iniciada a familiarização dos moradores com a linguagem arquitetônica. Nesse dia, também foi solicitado aos moradores que desenhassem como imaginavam sua casa, ou como gostariam que ela fosse (Figura 2). Aproximadamente 60 pessoas da comunidade participaram desse encontro, sendo que mais da metade participou ativamente das atividades e desenvolveu o desenho solicitado.

No encontro seguinte, os moradores levaram para a oficina seus desenhos, representando a casa que gostariam de ter e, a partir disso, ocorreu um diálogo sobre as diferentes alternativas de moradia, bem como sobre as necessidades de cada morador para a sua casa. Com base nesses diálogos, foi construído coletivamente um programa de necessidades básico para as habitações. Por fim, os moradores presentes foram divididos em grupos para a atividade seguinte, a qual envolveu a construção coletiva de maquetes com as propostas espaciais para suas moradias (Figura 3).

Figuras 2. Desenho de morador e

Figuras 3. Oficina com maquetes.

Fonte:

Registros de campo da pesquisa (SCOTTON,

2018)
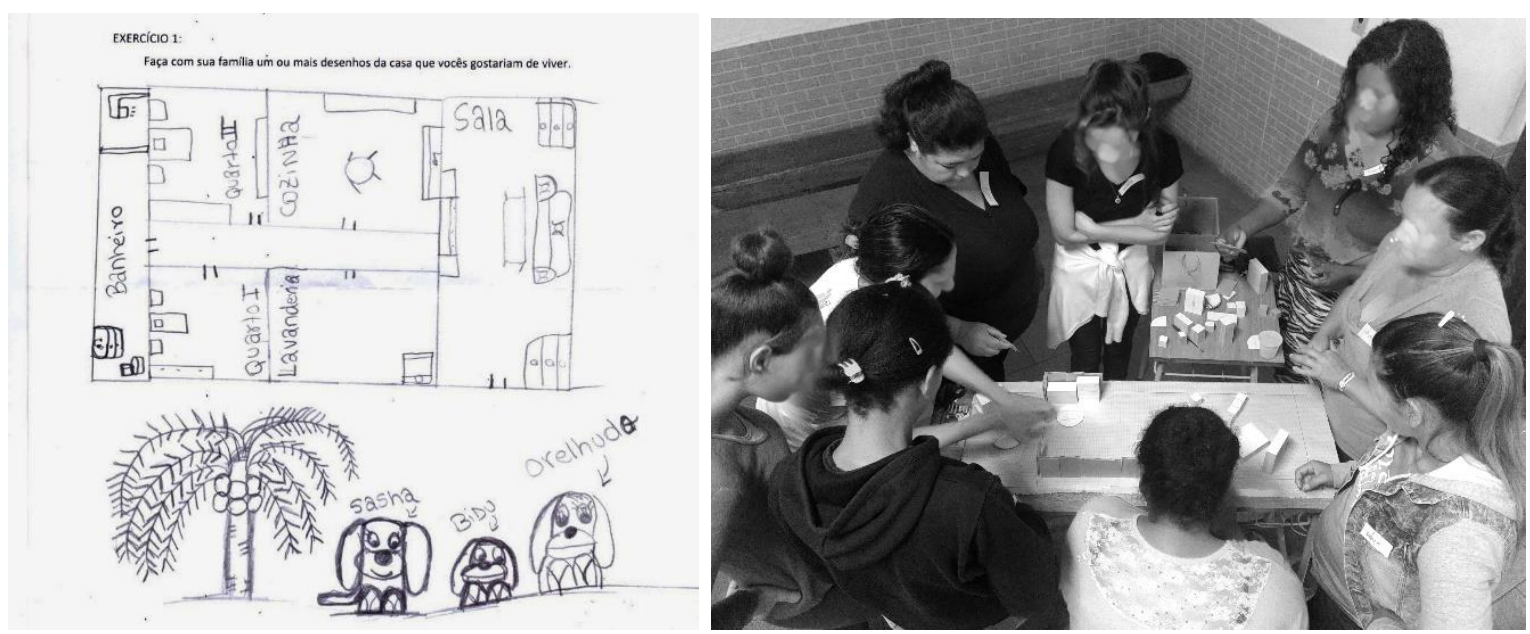
Por meio do exercício da maquete, surgiram questões específicas do perfil de cada família, como por exemplo: pessoas que viviam sozinhas, famílias que viviam em coabitação, casais com filhos, famílias com pessoas portadoras de necessidades especiais, pessoas que trabalhavam com comércio em casa. Para as diversas necessidades foram desenvolvidas diferentes propostas, sendo que todas foram registradas com fotos e utilizadas posteriormente pelos arquitetos, para o desenvolvimento dos projetos.

A partir desse encontro, os técnicos (arquitetos e urbanistas) que estavam conduzindo o processo participativo de ATHIS, passaram a desenvolver em escritório os projetos para cada uma das famílias. Assim, no encontro seguinte, foram apresentados aos moradores os projetos desenvolvidos pelos arquitetos. Também neste encontro, foi discutido com a comunidade o reaproveitamento de materiais para a construção (temática que surgiu a partir do diálogo com os moradores nas primeiras oficinas, onde o reaproveitamento de materiais foi identificado como uma realidade no contexto de catadores de resíduos). A equipe de arquitetos elencou diferentes alternativas de baixo custo que poderiam melhorar o espaço da moradia; sendo que também foram consideradas opções de utilização para os materiais que os moradores costumavam coletar, tais como: garrafas PET, madeiras e telhas metálicas.

Na sequência, a equipe de arquitetos iniciou os atendimentos individuais com os moradores, buscando ajustar os projetos às distintas necessidades de cada família. Para atender as dúvidas e questões dos moradores, os arquitetos realizaram plantões permanecendo na comunidade por turnos inteiros durante aproximadamente duas semanas. A fase de projeto para as habitações durou aproximadamente quatro meses.

Após finalizada, deu-se início à última etapa da Cooperação Técnica: a realização de oficinas prático-construtivas. Tais oficinas tiveram como objetivo contribuir para a ampliação do conhecimento dos moradores sobre as questões construtivas e arquitetônicas, bem como contribuir para uma autoconstrução de qualidade. No total foram realizadas 5 oficinas prático construtivas englobando diversas temáticas definidas durante o processo participativo, quando os moradores expuseram suas necessidades e dificuldades para a autoconstrução e os técnicos as contemplaram como conteúdo para as oficinas.

Assim, as duas primeiras oficinas práticas abordaram conteúdos sobre instalações hidráulicas e elétricas por serem instalações básicas para qualquer habitação. A temática das instalações elétricas surgiu quando os moradores manifestaram sua preocupação com incêndios causados por redes elétricas mal executadas na ocupação. Considerando a condição da autoconstrução, foi pertinente que estes moradores soubessem fazer suas instalações elétricas de maneira correta e segura. A oficina seguinte abordou a locação de obras (Figura 4) e foi realizada no terreno de um dos moradores. A partir dessa oficina e com a liberação dos terrenos pela entrega dos termos de posse às famílias, diversos moradores deram início à construção das suas casas. Os moradores com a ajuda da família, dos vizinhos e de conhecidos, iniciaram o processo de autoconstrução de suas casas. 
Figura 4. Oficina prático-construtiva de locação de obra.

Fonte: Registro de campo da pesquisa (SCOTTON, 2019)

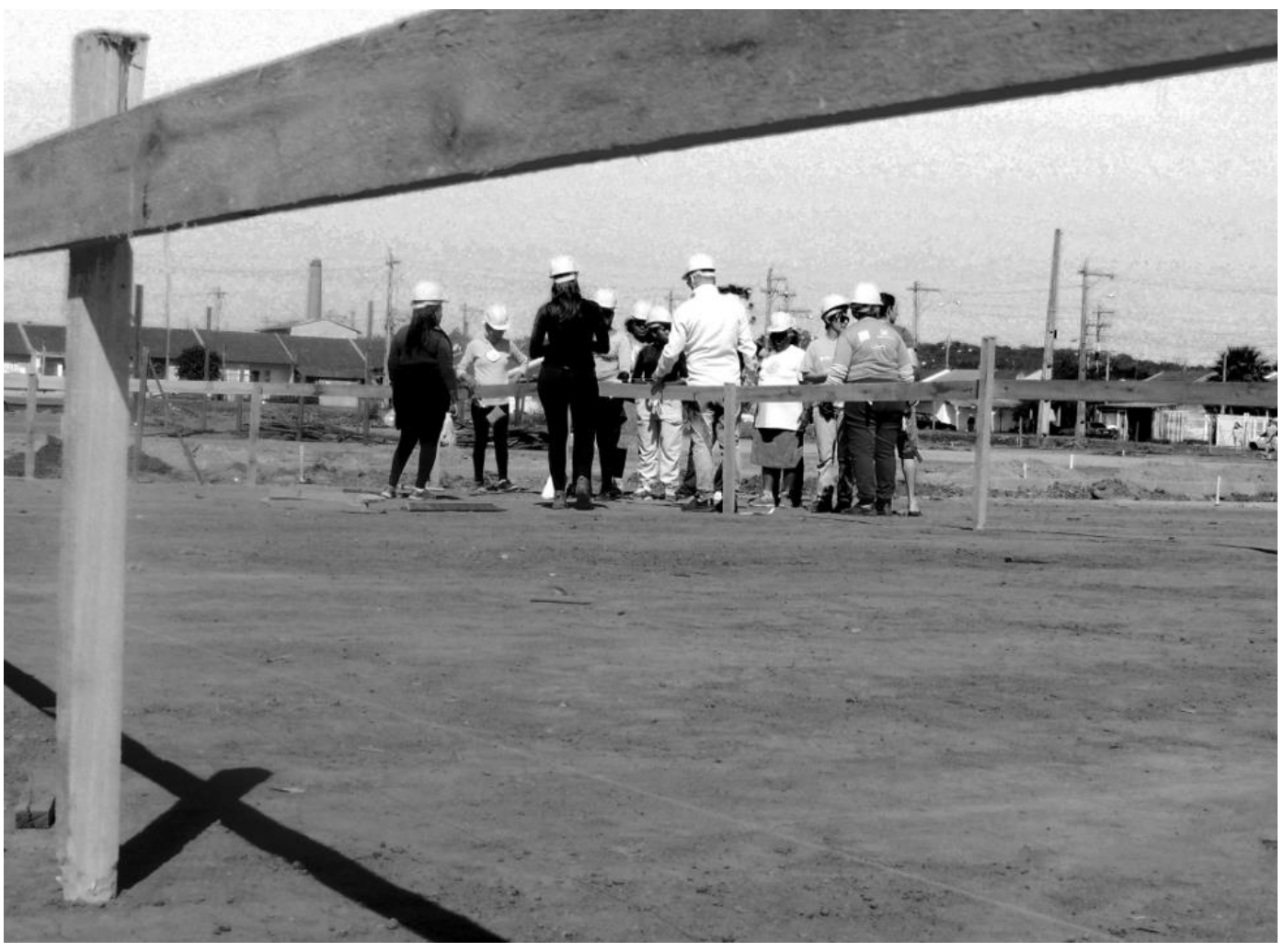

Nesse contexto, pôde-se observar a melhoria da qualidade construtiva das edificações principalmente daqueles moradores que participaram do processo de ATHIS e iniciaram a construção com o projeto em mãos. Infere-se, portanto, que a melhoria da qualidade construtiva se deu também como resultado da participação dos moradores no processo de ATHIS e dos conhecimentos adquiridos através dele.

Além disso, a segurança que a posse do terreno proporcionou, foi um grande incentivo para os moradores investirem na qualidade de sua habitação por se tratar agora de um lugar legalmente seu, sem o perigo de ser retirado dali a qualquer momento e perder todo o investimento feito.

\section{OS RESULTADOS DO PROCESSO DE ATHIS NA OCUPAÇÃO CER. ANITA}

A partir das entrevistas realizadas com técnicos e moradores, foi possível identificar algumas contribuições do processo de ATHIS para a melhoria do ambiente construído em um habitat mais saudável.

\section{PERCEPÇÃO DOS MORADORES}

As respostas dos moradores da Ocupação Cerâmica Anita apresentaram como destaque a melhoria das condições da moradia e da infraestrutura urbana do local, conquistados através do processo de ATHIS. As melhorias representaram uma considerável evolução: da condição precária e insalubre de ocupação (barro, esgoto e lona) para uma casa com instalações hidrossanitárias e elétricas e com abastecimento de água e de energia elétrica. Contudo, ressaltaram através das falas, a dificuldade de passar pelo processo de autoconstrução, dependendo dos exíguos recursos próprios para executar o que foi projetado; já que não foi viabilizado nenhum tipo de financiamento para a construção dos projetos das habitações. 
Apenas no que se referia à infraestrutura urbana, abertura de vias, instalações de rede elétrica e serviço de água, houve execução pela municipalidade com recursos públicos.

Dentre as melhorias, o que se destacou para os moradores foi a conquista dos serviços de água, luz e saneamento básico: "o que é nosso por direito" (frase de um dos moradores entrevistados). Os relatos dos moradores explicaram que as instalações clandestinas de energia elétrica, que existiam anteriormente, haviam causado incêndios e destruído várias casas na ocupação. Também mencionaram que, a partir do processo de ATHIS, a situação havia mudado, porque o fornecimento de energia acontecia de forma legal via rede pública.

Sobre o saneamento, os moradores descreveram a precariedade que existia antes do processo de ATHIS, com esgoto exposto e número reduzido de banheiros (apenas algumas habitações da ocupação possuíam banheiros). Após o processo de assistência técnica, cada casa havia sido construída com seu próprio banheiro, melhorando as condições de higienização e, se considerado o contexto de pandemia, as condições de prevenção dos moradores à COVID 19.

"Melhorou em tudo, primeiro o cara passava no meio de um corredorzinho cheio de vazamentos, agora tem a rua ali - antes era muito lixo, esgoto a céu aberto, agora eliminou muito rato e barata, melhorou $100 \%$ - antes tinha muito barro e muito lodo." 7

Ou seja, o acesso à infraestrutura que a situação legalizada permitiu, também apareceu nos relatos dos moradores como uma mudança essencial para um habitat saudável. Porque somente dessa forma, os investimentos e serviços públicos poderiam chegar ao local. Nesse sentido, as questões urbanas foram justamente as que receberam o maior número de comentários positivos mencionados pelos moradores. Nas respostas, eles estabeleceram constantes comparações entre a situação prévia da ocupação com a nova situação, consolidada a partir do processo da ATHIS. Na situação prévia, foram relatados problemas de: aglomeração de lixo e entulho, corredores estreitos; esgoto sem canalização, presença de ratos, insetos e baratas, bem como lotes de tamanhos diferentes e injustos (alguns moradores com lotes grandes e outros com lotes minúsculos). Já em relação à situação após o processo da ATHIS, foram mencionados: a definição e delimitação dos lotes em tamanhos iguais, o traçado projetado para as ruas, o fornecimento dos serviços básicos, e a consequente melhoria na limpeza e organização do local. Para a moradia especificamente, as respostas mencionaram com maior frequência a melhoria da qualidade construtiva das casas e a presença de banheiros em todas as habitações.

\section{PERCEPÇÃO DOS TÉCNICOS - ARQUITETOS E URBANISTAS}

As respostas dos técnicos nas entrevistas também mencionam a melhoria das condições de moradia do local, onde se partiu de uma condição precária, para uma organização urbana com estruturação de ruas, lotes e infraestrutura básica de saneamento. Também foi mencionado em destaque a presença de banheiro nas novas habitações. Essas conquistas foram retratadas como vitórias em direção à efetivação do direito à moradia em um habitat saudável.

Os técnicos apontaram que, alguns moradores, após esse processo, construíram casas de melhor qualidade pelo fato de estarem em uma condição permanente no local (posse), e também devido aos conhecimentos construtivos adquiridos no processo participativo de ATHIS. Além disso, também destacam a melhoria da qualidade urbana no local:

\footnotetext{
7 Trecho da fala de um dos moradores entrevistados.
} 
"A ATHIS levou a prefeitura a olhar para uma determinada comunidade e suas necessidades - o projeto acelerou o processo de assinatura da posse, se não fosse o nosso projeto sabe lá se eles iam ganhar a terra." 8

Consideraram, portanto, que o processo de ATHIS levou a prefeitura a investir na oferta de infraestrutura e serviços públicos (água, energia elétrica, arruamento) naquele local.

\section{CONTRIBUIÇÕES DO PROCESSO}

A assistência técnica se apresentou como um processo com potencial de contribuir, primeiramente, para a efetivação de projetos com maior qualidade arquitetônica, adequados a um habitat saudável, bem como para o atendimento das necessidades específicas das populações de baixa renda. Efetivando a intenção da Lei 11.888 de assegurar o direito à moradia previsto no Art. 6o da Constituição Federal e de qualificar o uso do espaço edificado e de seu entorno (BRASIL, 2008). Além disso, contribuiu também na efetivação do direito de uso dos serviços públicos de água e energia elétrica, através da posse e da regularidade do espaço de morar.

A melhoria da qualidade construtiva das moradias da Ocupação Cerâmica Anita, antes e depois do processo de ATHIS, é exemplificada nas figuras a seguir. A Figura 5 apresenta croquis do perfil das casas existentes antes do processo de ATHIS, onde as mesmas eram feitas de madeira, resumindo-se em sua grande maioria a um único ambiente sem divisórias, com metragem quadrada reduzida, muitas vezes sem ventilação e sem iluminação adequadas.

Figura 5. Croquis das habitações existentes na ocupação antes do processo de ATHIS

Fonte:

Registro de campo da pesquisa (SCOTTON, 2018)

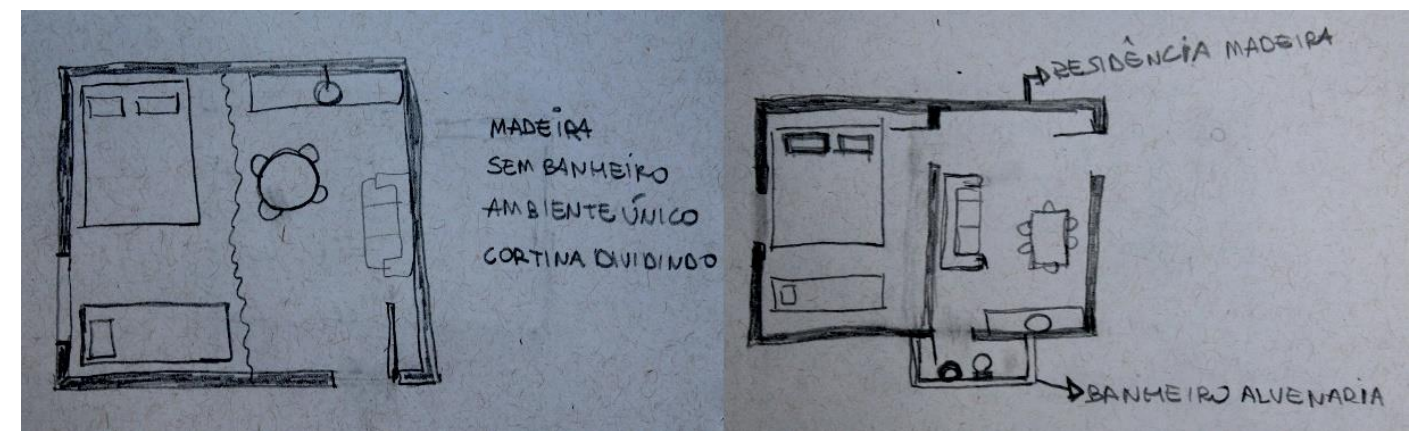

Na Figura 6 é possível observar uma das habitações originais da ocupação construída em madeira, antes do processo de ATHIS.

\footnotetext{
8 Trecho da fala de um dos técnicos entrevistados.
} 


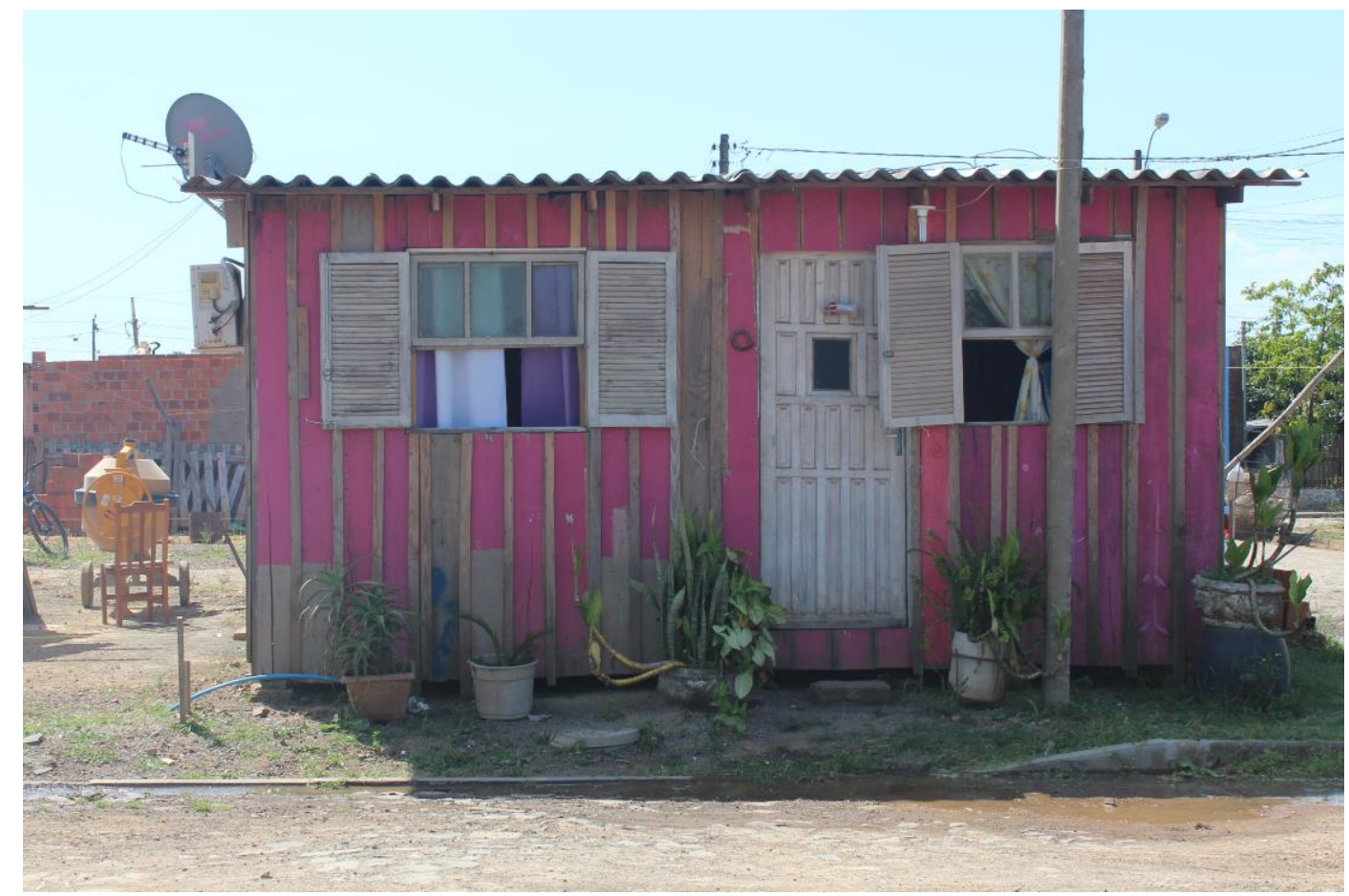

Na Figura 7 é apresentado um dos projetos desenvolvidos durante o processo de ATHIS. A habitação projetada apresenta boas condições de insolação e ventilação, equipamentos sanitários e instalações de água e de energia elétrica, a partir do fornecimento da rede pública. As habitações têm metragem quadrada coerente com o número de habitantes da família. Além disso, foram projetadas para serem construídas em estrutura mista: alvenaria nas áreas molhadas e madeira no restante da habitação. 0 uso da madeira para a construção foi uma solicitação dos moradores durante o processo de ATHIS, devido ao seu conhecimento prévio dessa técnica construtiva. Assim, os projetos foram adequados aos conhecimentos dos moradores, já que seriam executados através da autoconstrução.

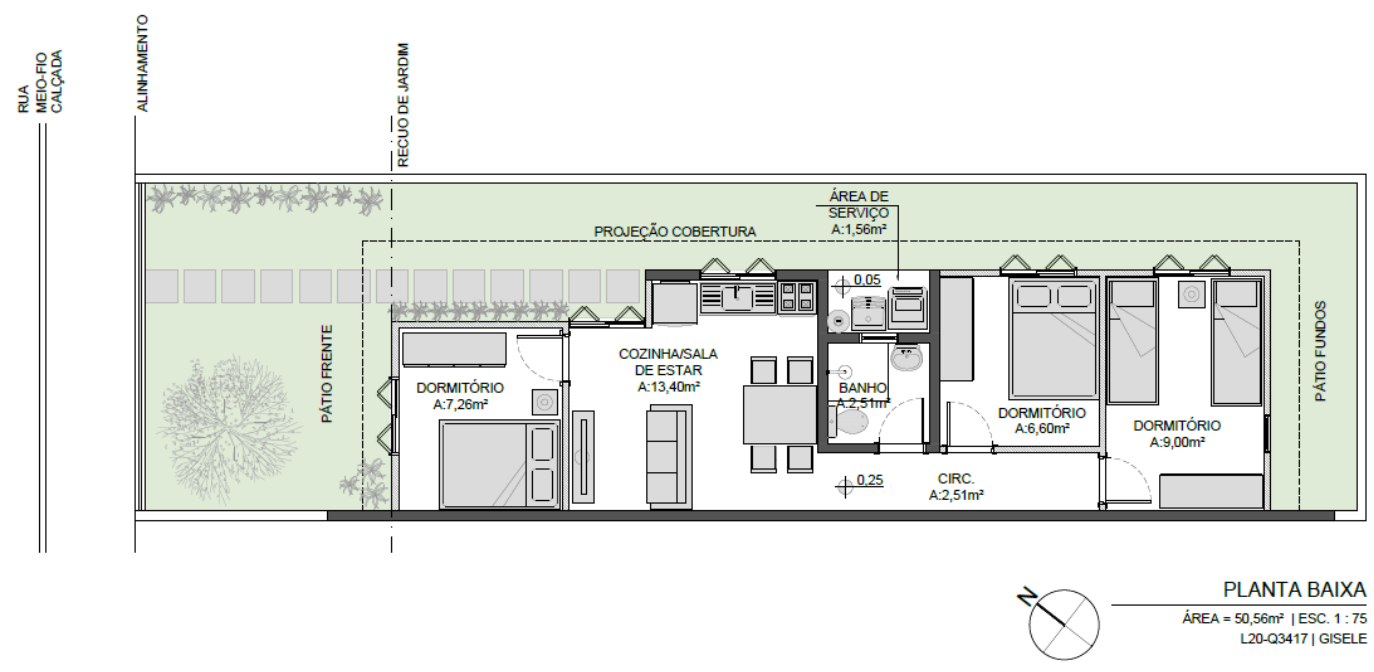

Dessa forma, o processo de ATHIS parece ter contribuído para melhoria da qualidade do ambiente construído (qualidade construtiva, salubridade, ventilação, iluminação etc.) e, consequentemente, para a consolidação de um habitat mais saudável para aquelas famílias. A partir da existência de instalações (hidrossanitárias e elétricas) conectadas ao fornecimento
Figura 6. Perfil das habitações existentes na ocupação antes do processo de ATHIS

Fonte:

Registro de campo da pesquisa (SCOTTON, 2019).
Figura 7. Resultado projetual desenvolvido pelos arquitetos no processo de ATHIS.

\section{Fonte:} IAB/RS (2018). 
de serviços das redes públicas, foi possível proporcionar as condições preventivas mínimas recomendadas para evitar a propagação da COVID-19, como a higienização constante das mãos e o isolamento social em ambiente salubre. 0 que, além de beneficiar cada morador em seu lar, beneficia a sociedade como um todo.

Por fim, salienta-se, no caso desse processo de ATHIS, a importância da abordagem participativa, a qual permitiu evidenciar as diferentes necessidades presentes na realidade da comunidade, que só puderam ser visualizadas com a aproximação dos técnicos ao contexto. Além disso, através do processo participativo os moradores puderam expor seus conhecimentos; o que permitiu a consolidação de projetos que representassem uma interação entre os conhecimentos técnicos (dos arquitetos que conduziram o processo) e os conhecimentos populares (dos moradores daquela comunidade).

\section{CONSIDERAÇÕES FINAIS}

Conforme apresentado anteriormente, o objetivo deste trabalho foi compreender como o processo de ATHIS pode contribuir para a promoção do habitat saudável para a comunidade estudada. No contexto do estudo de caso, a ATHIS realizada através do processo participativo de projeto proporcionou melhorias condizentes com os requisitos de: 1) moradia digna; 2) acesso à habitação e à cidade; 3) adequação às especificidades do morador; 4) qualidade da moradia; 5) qualidade urbana; e 6) segurança de posse. Foram constatadas melhorias das condições de habitabilidade das habitações através da promoção da posse dos terrenos, da disponibilização de infraestrutura urbana e dos serviços de água, saneamento e energia elétrica. Além disso, o processo participativo de projeto contribuiu para a melhoria da qualidade construtiva das habitações através do conhecimento repassado aos moradores pelos técnicos, referente às técnicas construtivas condizentes com o processo de autoconstrução e ao uso correto dos materiais.

Por fim, foi observado que a assistência técnica aliada aos processos participativos tem um grande potencial para se consolidar como uma prática de produção habitacional mais adequada e satisfatória à realidade das populações de baixa renda, possibilitando o acesso a um habitat saudável e atendendo suas necessidades específicas. Assim, neste trabalho foi possível constatar que: 1) a assistência técnica, envolvendo a população através de processo participativo, pode contribuir para a melhoria das condições de habitabilidade das comunidades envolvidas (pois a partir do envolvimento no processo, os moradores adquirem certos conhecimentos que lhes permite construir com maior qualidade); 2) a ATHIS pode contribuir para a consolidação de um habitat saudável através da melhoria da qualidade do ambiente urbano e habitacional, destacando-se o atendimento de condições básicas de saneamento. As melhorias constatadas no processo de ATHIS estudado assumiram uma importância ainda maior se considerado o atual contexto da pandemia de COVID-19.

Todavia, os resultados não devem ser generalizados e muitos estudos sobre o tema ainda se fazem necessários. Para trabalhos futuros, sugere-se a ampliação da investigação das contribuições do processo de ATHIS para a melhor gestão das necessidades da população de baixa renda e para a prevenção de doenças que possam ser disseminadas em aglomerados subnormais e em empreendimentos habitacionais. 


\section{Referências Bibliográficas}

AMORE, C. S. ASSESSORIA E ASSISTÊNCIA TÉCNICA: arquitetura e comunidade na política pública de habitação de interesse social. In: II Seminário Nacional sobre urbanização de favelas - URBFAVELAS, Rio de Janeiro, 2016. Disponível em <http://www.peabirutca.org.br/wp-content/uploads/athis2.pdf>. Acesso em 20 de outubro de 2019.

BETIM, F. Tuberculose na Rocinha expõe o Brasil que estacionou no século XIX: favela do Rio de Janeiro tem uma das maiores taxas de incidência da doença no país. El País, Rio de Janeiro, 12 set. 2015.

BOLDRINI, P. (2012). Producción participativa del hábi-tat popular en el área metropolitana de Tucumán (Tesis doctoral). Facultad de Filosofía y Letras (UNT), Tu-cumán.

BOLDRINI, P; MALIZIA, M. Mejora participativa del hábitat en contextos de desigualdad en ciudades intermedias. Hábitat y Sociedad (issn 2173-125X), n. o 13, noviembre de 2020, Universidad de Sevilla, pp. 209-228http://dx.doi.org/10.12795/HabitatySociedad.2020.i13.12

BRASIL, Constituição (1988).

BRASIL. Lei no 11.888, de 24 de dezembro de 2008. Disponível em: <http://www.planalto.gov.br/ccivil_03/_Ato2007-2010/2008/Lei/L11888.htm>. Acesso em: jan. 2020.

CANETTIERI, T. Periferia e a Luta por Moradia e Pela Vida em Tempos de Pandemia: Cenários e Desafios. Rev. Ipê Roxo - Jardim/MS, v. 2, n. 1, p. 49-61, 2020.

DOBRY, S. A. Arquitetura e urbanismo participativos: uma gênese. V!RUS, São Carlos, n. 18, 2019. [online]. Disponível em: <http://www.nomads.usp.br/virus/virus18/?sec=4\&item=4\&lang=pt>. Acesso em: 08 Jul. 2019.

D'OTTAVIANO, Camila (Org.) ; ROVATI, João Farias (Org.). Para além da sala de aula. Extensão Universitária e Planejamento Urbano e Regional. 1. ed. São Paulo: FAUUSP/ANPUR, 2017. v. 1. 146 p.

D'OTTAVIANO, Camila (Org.) ; ROVATI, João Farias (Org.). Além dos muros da Universidade: planejamento urbano e regional e Extensão Universitária. 1. ed. São Paulo: FAUUSP, 2019. v. 1. 202p.

FRIZZI, G.; PINHO, C. M. D. DE. ÍNDICE DE ACESSO À MORADIA DIGNA: Construção metodológica e resultados para o município de Santo André, SP. XVIII ENANPUR - Encontro Nacional da Associação Nacional de Pós-Graduação e Pesquisa em Planejamento Urbano e Regional. Natal, 2019. Disponível em <http://anpur.org.br/xviiienanpur/anaisadmin/capapdf.php?reqid=775>. Acesso em 5 de setembro de 2019 .

FUNDAÇÃO JOÃO PINHEIRO. Estatística e Informações: demografia e indicadores sociais: déficit habitacional no Brasil: 2015. Diretoria de Estatística e Informações (DIREI). Coordenação das Estatísticas Urbano Ambientais, 2018.

HOUAISS, Antônio. Dicionário Houaiss da Língua Portuguesa. Rio de Janeiro, Ed. Objetiva, 2001.

INSTITUTO BRASILEIRO DE GEOGRAFIA E ESTATÍSTICA (IBGE).. Rio de Janeiro, 2012. Censo Brasileiro de 2010

MARICATO, E. Brasil, Cidades: alternativas para a crise urbana. Petrópolis: Editora Vozes, 2002.

MARICATO, E. Para entender a crise urbana. São Paulo, Expressão Popular, 2015. 
Josiane A. Scotton

josianeascotton@gmail.com

Luciana I. G. Miron

lumiron@gmail.com

Inês Martina Lersch

martina.lersch@ufrgs.br
MELLO, B. C. E. ; LERSCH, I. M. ; NODARI, G. R.; ROVATI, J. F. . Práticas Urbanas Emergentes. 1. ed. Porto Alegre: UFRGS, 2019. v. 1. 225p.

MELLO, B. C. E.; LERSCH, I. M. (Org.); ROVATI, J. F. (Org.); FINGER, B. B. (Org.); SILVA, H. M. (Org.). Práticas Urbanas Emergentes, ano II: extensão e assessoria técnica. 1. ed. Porto Alegre: Ed. dos Autores, 2020. v. 1. 241p.

MORADO NASCIMENTO, Denise; TOSTES, S. P. ; SOARES, A. C. B. ; BOAVENTURA, C. A. ; SANTOS, C. R. A. dos . Diálogos: Possibilidades de Processos de Projeto Compartilhados. Cadernos de Pós Graduação em Arquitetura e Urbanismo (Mackenzie. Online), v. 10, p. 179-197, 2010.

NAÇÕES UNIDAS. Comentário geral no 4 do Comitê sobre Direitos Econômicos Sociais e Culturais: o direito à habitação adequada, 1991. In: Por uma cultura de Direitos Humanos: Direito à moradia Adequada. Secretaria de direitos humanos, Brasília, 2013.

NASCIMENTO, DENISE MORADO. Lavar as mãos contra o Coronavírus: mas, e a Água? APS EM REVISTA, v. 2, p. 66-69, 2020.

NERY, C. Extrema pobreza atinge 13,5 milhões de pessoas e chega ao maior nível em 7 anos. 07/11/2019. Agência IBGE. Disponível em: <https://agenciadenoticias.ibge.gov.br/agencianoticias/2012-agencia-denoticias/noticias/25882-extrema-pobreza-atinge-13-5-milhoes-depessoas-e-chega-ao-maior-nivel-em-7-anos> Acesso em: 20 nov. 2020.

OLIVEIRA, L. A. DE. Processos Projetuais Participativos: Investigando as Contribuições em Usina e Habitat. Dissertação (Programa de Pós-Graduação em Desenvolvimento Urbano). Universidade Federal de Pernambuco, 2014.

PELLI, Victor. Habitar, Participar, Pertenecer. Acce-der a la vivienda-incluirse en la sociedad. Buenos Aires: Nobuko, 2007.

SAERGS. Programa ATME - Assistência Técnica Gratuita à Moradia Econômica. Editora Pr ed. Porto Alegre, 1977. 